\title{
Examination of associations between personality traits, and polymorphisms of MAO-A and 5-HTT with the severity of menopausal symptoms and depression levels
}

\author{
SEDIGHE ESMAEILZADEH ${ }^{1}$, MOULOUD AGAJANI DELAVAR ${ }^{1}$, HAMIDREZA NOURI $^{2}$, \\ SEPIDEH MASHAYEKH-AMIRI ${ }^{3}$, NILOUFAR AHMADI ${ }^{3}$ and REZA NAMDAR ${ }^{4}$ \\ ${ }^{1}$ Infertility and Reproductive Health Research Center, Health Research Institute; \\ ${ }^{2}$ Cellular and Molecular Biology Research Center; ${ }^{3}$ Student Committee Research; \\ ${ }^{4}$ Shahid Yahya Nezhad Hospital, Babol University of Medical Sciences, \\ Babol, Mazandaran 47135-547, Iran
}

Received June 15, 2019; Accepted December 23, 2019

DOI: $10.3892 / b r .2020 .1287$

\begin{abstract}
The aim of the present study was to investigate the association between different personality traits with monoamine oxidase A (MAO-A) and serotonin transporter (5-HTT), and to examine their effects on the severity of menopause symptoms as well as the levels of depression in menopausal women. The study was designed as an analytical cross-sectional study, performed on 132 healthy post-menopausal women in Iran. Personality was assessed using the Revised Edition of the NEO Personality Index (Neuroticism-Extroversion-Openness-Five Factor Inventory). The symptoms score sheet, used for measuring menopausal symptoms, was used to classify the participants according to their menopausal symptoms. Furthermore, Beck Depression Inventory short version was also used to assess depressive symptoms. Examination of blood samples taken from all participants was to identify DNA polymorphisms of 5-HTT using PCR. The results of the present study showed that a high level of neuroticism $(\mathrm{P}<0.0001)$, low levels of extroversion $(\mathrm{P}<0.002)$, an openness to experience $(\mathrm{P}=0.039)$ and conscientiousness $(\mathrm{P}=0.001)$ were all positively associated with the severity of menopausal symptoms. In addition, a high level of neuroticism $(\mathrm{P}<0.0001)$, low levels of extroversion $(\mathrm{P}<0.0001)$, and a low level of agreeableness $(\mathrm{P}<0.024)$ and conscientiousness $(\mathrm{P}<0.0001)$ were all positively associated with depressive symptoms. There was no statistically significant association between MAO-A and 5-HTT polymorphisms with menopause and depression scores. Based
\end{abstract}

Correspondence to: Professor Mouloud Agajani Delavar, Infertility and Reproductive Health Research Center, Health Research Institute, Babol University of Medical Sciences, Babol-Amol Old Highway, Babol, Mazandaran 47135-547, Iran

E-mail: moloodaghajani@yahoo.com

Key words: post-menopause, climacteric, personality, depression, genetic polymorphism, 5-HT transporter, monoamine oxidase-A on these results, there appears to be a significant association between personality traits with both depression and menopausal symptoms. Identification of homogeneous groups of women who are predisposed to depression and severe menopausal symptoms may allow for the implementation of early prevention programs.

\section{Introduction}

A wide range of somatic disorders, psychiatric symptoms, sexual problems and vasomotor symptoms have been reported in menopausal women $(1,2)$. It is also hypothesized that there are numerous clinical menopausal symptoms associated with hormonal changes, particularly estrogen deficiency; however, the physiological mechanisms by which estrogen modulates these symptoms remain unknown $(3,4)$. Furthermore, there appears to be a wide range of menopausal symptoms which remain unknown (4). The personality of individuals is most likely to change between 50-65 years of age, and is supposedly in response to both physical and social circumstances (5). Similarly, several studies have demonstrated that personality traits may intensify menopausal symptoms $(6,7)$.

Personality is an aspect of human life that can predict an individual's reaction to different situations. It is hypothesized that an individual's personality is the combination of traits and patterns, and that both environmental and genetic factors could, to a large extent, contribute to the formation of personality traits; the impact of environmental factors, particularly a deficiency of vitamin D (from living in regions without much sun or overcast regions), tend to affect anxiety, osteoporosis, quality of life and the development of personality $(2,8-10)$. There are five personality traits: Conscientiousness, agreeableness, neuroticism, openness to experience and extroversion. Neuroticism is a tendency to exhibit negative emotions, such as depression, anxiety or anger. Extroversion is associated with socialization, excitement and partaking in activities. Agreeableness, is considered a super trait personality among the five traits, and is characterized as being cooperative, caring, nurturing of others and affectionate (11). An openness 
to experience is the desire of an individual to be curious and sensitive to natural beauty, and is associated with an affinity for art. Conscientiousness is associated with generosity, empathy, cooperation and trust (12). Studies have shown that personality traits tend to be inheritable, and that there may be a genetic basis for personality $(13,14)$.

Numerous studies have demonstrated that serotonin [5-hydroxytryptamine (5-HT)] serves an important role in regulating activity of the central nervous system, and that it can affect a wide range of psychological processes, including individual differences in personality traits $(15,16)$. Additionally, several studies have demonstrated that a reduction in 5-HT levels serves an important role in the onset of depression $(17,18)$. In this regard, polymorphisms in the promoter region of the monoamine oxidase-A (MAO-A) gene may intensify the degree of depression (19). Jurczak et al (20) identified that there was a significant correlation between the allele frequency of a 30-bp variable number tandem repeat (VNTR) polymorphism in the promoter region of MAO-A and depression, as well as between the allele frequency of polymorphisms in the 5-HT transporter (5-HTT) gene and the severity of menopausal symptoms in postmenopausal women. However, Grochans et al (21) demonstrated that the presence of a 44-bp 5-HTT-LPR polymorphism was significantly more frequently observed in women with severe menopausal symptoms, but there was no significant association between the genotype distribution in the MAO-A promoter region and the severity of menopausal symptoms. Several women experience symptoms for months or even years after their menopause, and this constitutes a major challenge for the social sciences and modern medicine (22-24). Thus, it is imperative to identify personality traits and genes that contribute to the severity of menopausal and depressive symptoms. Although it has been suggested that personality traits and genes are associated with severe menopausal and depressive symptoms, there are inconsistencies between reports on the association between personality traits, genes, depression and the severity of menopausal symptoms $(21,25,26)$. In addition, to the best of our knowledge, there are no such investigations on Iranian patients. The aim of the present study was to investigate the effect of personality traits, and polymorphisms of MAO-A and 5-HTTon the severity of menopausal and depressive symptoms in menopause women.

\section{Patients and methods}

Patients. A cross-sectional study was performed on 132 healthy post-menopausal women with a mean age \pm standard deviation of 54.3 \pm 4.1 years (range, 45-65) in Babol (Iran). The study was approved by The Ethics Committee of Babol University of Medical Sciences (approval no. MUBABOL,HRI.REC.1395.7; Babol, Iran) and was performed according to guidelines described in the Declaration of Helsinki (27). The sample was selected from primary health care centers in Babol using a cluster sampling method between September 2016 and August 2018. At first, several clusters were randomly selected from primary health care centers and then all eligible individuals in each cluster (based on household records at the clinic) were included in the study.

The inclusion criteria for the study were as follows: Women aged between 45-65 years; able to fill in the questionnaire with the help of a researcher; final menstruation occurred at least 1 year prior to the study; normal cervical smear test results; and no history of thyroid disease, breast cancer or stroke. The exclusion criteria for the study were: Post-menopausal women with endocrine disorders, chronic diseases or acute disorders; any type of cancer and had to use hormone replacement therapy during the previous 6 months; former and current smokers; those who consumed at least one unit of alcohol per day; those with secondary amenorrhea and who had ovarian surgery; had undergone hysterectomy, chemotherapy or radiotherapy; and those with mental disorders.

Written consent was provided by each participant prior to beginning the study. The participants were free to continue the study or withdraw from it at any point. Participants' weight, height, blood pressure and body mass index (BMI) were assessed. Women's bodyweight was measured with minimal clothing and without shoes using a digital scale. Their height was measured to the nearest $\mathrm{cm}$ (28). BMI was calculated using the formula: Weight $(\mathrm{kg}) /$ height $^{2}(\mathrm{~m})$, which categorized the participants into two groups: BMI $<25$ and $\geq 25 \mathrm{~kg} / \mathrm{m}^{2}(29)$. The menopausal status was assessed through a gynecological interview and a questionnaire. The participants were divided in to three groups according to their menopausal age: $<45$, 45-50 and 50-57 (30).

The survey was conducted in two phases. The first phase of the survey was a diagnostic study using a socio-demographic questionnaire and standard research instruments for personality, menopausal symptom and depression diagnosis and the second phase was based on genetic tests.

Socio-demographic questionnaire. The socio-demographic questionnaire sought information on age, marital status, educational level, occupation, the number of parities and the number of abortions. The participants were divided into two groups according to their age: 45-55 and 56-65. The education level of the participants was categorized into two levels: Under diploma and diploma/over diploma. The marital status was classified as: Married, single, divorced or widowed. Occupation was classified as in work or out of work. Women were also categorized into three groups based on the history of abortion: Induced abortion, spontaneous abortion and no history of abortion. The parity of the women was divided into two groups: $\leq 3$ and $>3$ births.

Symptom score sheet. The symptom score sheet (Modified Greene Scale) (31-33), is a standard measure of menopausal symptoms used in a variety of studies. The sheet includes 20 questions regarding menopausal symptoms and the severity of symptoms, all in a four-point-likert scale for each symptom from 0 (none) to 3 (severe). The women were classified into two categories based on their menopausal symptoms: Minor or no symptoms, $0-15$; and severe menopausal symptoms, $\geq 15$. The construct validity and the reliability of the score sheet were assessed based on a number of previous studies (33-35). Additionally, the validity and reliability of the Persian version of the symptoms score sheet has already been assessed (36).

Beck Depression Inventory (BDI-13). BDI-13, which was developed by Beck (1972), was used to assess depressive symptoms (37). Its coefficients were obtained from 0.75 to 
Table I. Socio-demographic characteristics, reproductive history and body mass index of participants.

\begin{tabular}{lc}
\hline Characteristics & $\mathrm{n}(\%)$ \\
\hline Age, years & \\
$45-55$ & $84(63.6)$ \\
$56-65$ & $48(36.4)$ \\
Education & \\
Under diploma & $104(78.8)$ \\
Diploma/over diploma & $28(21.2)$ \\
Menopause age, years & \\
$<45$ & $17(12.9)$ \\
$45-50$ & $75(56.8)$ \\
$50-57$ & $40(30.3)$ \\
Marital status & \\
Married & $124(93.9)$ \\
Single/divorced/widowed & $8(6.1)$ \\
Occupation & \\
In work & $118(89.4)$ \\
Out work & $14(10.6)$ \\
Abortion & \\
Induced & $15(11.4)$ \\
Spontaneous & $26(19.7)$ \\
No abortion & $91(68.9)$ \\
Body mass index, $\mathrm{kg} / \mathrm{m}^{2}$ & \\
$<25$ & $32(24.2)$ \\
$\geq 25$ & $100(75.8)$ \\
Parity & \\
$\leq 3$ & $71(53.8)$ \\
$>3$ & $61(46.2)$ \\
\hline &
\end{tabular}

0.83 . Items are rated on a $0-3$ point scale $(0$, none; 3 , severe symptom manifestation). A possible score on the BDI could range from 0-39; thus, a higher score means a higher severity of depression. An index score of $\leq 4$ indicates none or minimal depression, 5-7 mild, 8-15 moderate, and $\geq 16$ severe (38). The reliability and validity of this questionnaire was verified by Rajabi (39) in Iran.

Neuroticism-Extroversion-Openness-Five Factor Inventory (NEO-FFI). The short form of the NEO questionnaire is comprised of 60 items which evaluates 5 factors including, neuroticism, extraversion, openness to experience, conscientiousness and agreeableness. NEO-FFI is measured based on a 5-point Likert scale from 'strongly disagree' to 'strongly agree'. The questionnaires suitability has been validated is one of the most widely used questionnaires for screening personality (40). Garousi Farshi et al (41) verified the reliability and validity of this self-reported personality questionnaire for screening personality with Iranian individuals.

Polymerase chain reaction (PCR). Venous blood samples were obtained from each participant for genetic testing and then transferred to EDTA tubes. Genomic DNA was extracted using the Miller Salt Out method (42). The DNA was isolated from the whole blood and stored at $-20^{\circ} \mathrm{C}$. The $P C R$ procedure was used for detecting polymorphisms $(43,44)$. The aim of the analysis was to amplify the 30-bp promoter region VNTR in the MAO gene. PCR was performed separately in $20 \mu \mathrm{l}$ reaction volume containing $50 \mathrm{ng}$ genomic DNA, $12.5 \mathrm{pmol}$ of each primer, $1.2 \mu 1 \mathrm{MgCl}_{2}(25 \mathrm{mM}), 0.8 \mu \mathrm{ldNTP}(10 \mathrm{mM})$, $2 \mu 1$ 10x reaction buffer and 1.5 units Taq polymerase (Parstous Biotech). The following primers were used: Forward, 5'-CCC AGGCTGCTCCAGAAA-3' and reverse, 5'-GGACCTGGG CAGTTGTGC-3'. The thermocycling conditions were: Primary denaturation $95^{\circ} \mathrm{C}$ for $3 \mathrm{~min}$; followed by 34 cycles of denaturing at $94^{\circ} \mathrm{C}$ for $40 \mathrm{sec}$, annealing at $57^{\circ} \mathrm{C}$ for $35 \mathrm{sec}$, polymerization at $72^{\circ} \mathrm{C}$ for $50 \mathrm{sec}$; and a final elongation step of $72^{\circ} \mathrm{C}$ for $10 \mathrm{~min}$. The amplified fragment sizes were: 239, 209, 226 and 269 bp $(45,46)$. For analysis of the 5-HTT gene, the fragment including the 44-bp insertion/deletion in the regulatory sequence (the presence or the lack of 44-bp) polymorphism was amplified. The sequences of the primers were HTT forward, 5'-GCGCTCCTGCATCCCCCATTA-3' and reverse, 5'-GGGATGCGGGGGAATACTGGT-3'. The thermocycling conditions were: Initial denaturation at $95^{\circ} \mathrm{C}$ for $2 \mathrm{~min}$; followed by $35 \mathrm{cycles}$ of $95^{\circ} \mathrm{C}$ for $60 \mathrm{sec}, 62^{\circ} \mathrm{C}$ for $60 \mathrm{sec}$ and $72^{\circ} \mathrm{C}$ for $60 \mathrm{sec}$; with a final extension step of $72^{\circ} \mathrm{C}$ for $10 \mathrm{~min}$. The genotype-specific PCR products were analyzed using 3\% agarose gel electrophoresis, then visualized under UV light after staining with ethidium bromide, and images were captured using a Gel Imaging system (Vilber Lourmat Deutschland $\mathrm{GmbH}$ ). Among the PCR products, fragment sizes with lengths of $253 \mathrm{bp}$ (small, S) and $297 \mathrm{bp}$ (long, L) were detected and three genotypes, including $\mathrm{S} / \mathrm{S}, \mathrm{L} / \mathrm{S}$ and $\mathrm{L} / \mathrm{L}$, were subsequently determined (47).

Statistical analysis. All analyses were performed using SPSS version 16.0 (SPSS, Inc.). Descriptive statistics are presented as the mean \pm standard the standard deviation and frequencies (\%), and were used to describe the socio demographic characteristics, reproductive history and body mass index of the participants. A $\chi^{2}$ test was used to verify the null hypothesis, referring to the independence of the analyzed variables. $\mathrm{P}<0.05$ was considered to indicate a statistically significant difference.

\section{Results}

Of the patients recruited, $78.8 \%$ of patients had completed elementary level only, $10.6 \%$ were employed, $94 \%$ were married and $18.2 \%$ had received hormone therapy. The mean $\mathrm{BMI} \pm$ standard deviation was $28.7 \pm 4.6 \mathrm{~kg} / \mathrm{m}^{2}$. The majority of women recruited were overweight or obese ( $70 \%$ of the women had a BMI $\geq 25 \mathrm{~kg} / \mathrm{m}^{2}$ ). The mean age \pm standard deviation at menopause was $48.3 \pm 4.2$ years (Table I).

According to the symptoms score sheet, $59.1 \%$ of the participants had severe menopausal symptoms and $40.9 \%$ had minor or no symptoms. Personality structure based on NEO-FFI were: Low and medium levels of neuroticism in $77.4 \%$ and high levels in $29.5 \%$ of the participants; and high levels of extroversion, agreeableness and conscientiousness in $\sim 50 \%$ of the participants. Low levels of openness to experience were reported by $75.8 \%$ of the respondents and high levels in 
Table II. Association of personality traits with menopausal symptoms in Baboli women aged 45-65 years old.

\begin{tabular}{|c|c|c|c|c|c|}
\hline NEO-FFI & Total, $\mathrm{n}=132$ & $\begin{array}{c}\text { Minor menopausal } \\
\text { symptoms, } n=54\end{array}$ & $\begin{array}{c}\text { Severe menopausal } \\
\text { symptoms, } n=78\end{array}$ & $\chi^{2}$ & P-value \\
\hline Neuroticism, n (\%) & & & & 25.125 & $<0.0001^{\mathrm{b}}$ \\
\hline Low & $32(24.2)$ & $25(78.1)$ & $7(21.9)$ & & \\
\hline Average & $61(46.2)$ & $20(32.8)$ & $41(67.2)$ & & \\
\hline High & $39(29.5)$ & $9(23.1)$ & $30(76.9)$ & & \\
\hline Extroversion, n (\%) & & & & 12.582 & $0.002^{\mathrm{a}}$ \\
\hline Low & $29(22.0)$ & $4(13.8)$ & $25(86.2)$ & & \\
\hline Average & $30(22.7)$ & $12(40.0)$ & $18(60.0)$ & & \\
\hline High & $73(55.3)$ & $38(52.1)$ & $35(47.9)$ & & \\
\hline Openness, n (\%) & & & & 6.513 & $0.039^{\mathrm{a}}$ \\
\hline Low & $100(75.8)$ & $36(36.5)$ & $64(64.0)$ & & \\
\hline Average & $23(17.4)$ & $11(47.8)$ & $12(52.2)$ & & \\
\hline High & $9(6.8)$ & $7(77.8)$ & $2(22.2)$ & & \\
\hline Agreeableness, n (\%) & & & & 5.118 & 0.077 \\
\hline Low & $33(25.0)$ & $10(30.3)$ & $23(69.7)$ & & \\
\hline Average & $41(31.1)$ & $14(34.1)$ & $27(65.9)$ & & \\
\hline High & $58(43.9)$ & $30(51.7)$ & $28(48.3)$ & & \\
\hline Conscientiousness, n (\%) & & & & 14.112 & $0.001^{\mathrm{b}}$ \\
\hline Low & $10(7.6)$ & $1(10.0)$ & $9(90.0)$ & & \\
\hline Average & $39(29.5)$ & $9(23.1)$ & $30(76.9)$ & & \\
\hline High & $83(62.9)$ & $44(53.0)$ & $39(47.0)$ & & \\
\hline
\end{tabular}

${ }^{\mathrm{a}} \mathrm{P}<0.05,{ }^{\mathrm{b}} \mathrm{P}<0.001$. NEO-FFI, Neuroticism-Extroversion-Openness-Five Factor Inventory.

6.8\%. A high level of neuroticism $(\mathrm{P}<0.0001)$, a low level of extroversion $(\mathrm{P}<0.002)$, openness to experience $(\mathrm{P}=0.039)$ and conscientiousness $(\mathrm{P}=0.001)$ were all associated with severe menopausal symptoms, but agreeableness was not significantly associated with symptoms (Table II).

Based on BDI, depressive symptoms were diagnosed in $53.8 \%$ and the other $46.2 \%$ of the participants had no depressive symptoms at all. A high level of neuroticism $(\mathrm{P}<0.0001)$, low levels of extroversion $(\mathrm{P}<0.0001)$, low levels of agreeableness $(\mathrm{P}<0.024)$ and conscientiousness $(\mathrm{P}<0.0001)$ were all associated with depressive symptoms, where as an openness to experience was not significantly associated (Table III).

A statistically significant difference was not observed between the distribution of polymorphisms in the promoter regions of 5-HTT-LPR and MAO-A and the severity of menopausal symptoms (Table IV). In addition, there was no association between 5-HTT-LPR and MAO-A polymorphisms and depression (Table V).

\section{Discussion}

In the present study, it was shown that women with a high level of neuroticism had severe menopausal symptoms and depressive symptoms. Additionally, menopausal women with low levels of extroversion, openness to experience or conscientiousness had severe menopausal and depressive symptoms. Menopausal women with low levels of agreeableness had depressive symptoms only with no evidence menopausal symptoms.
These results are in agreement with a previous study where a positive correlation between menopause status and neuroticism was identified (6). The results of the present study are also consistent with the results of a study of Iranian patients that reported a significant relationship between conscientiousness score and the severity of hot flashes and night sweats (48). Depression is frequently observed in menopausal women (49), and several studies have demonstrated the association between personality traits and depression $(50,51)$. Additionally, the relationship between depression and higher scores of neuroticism (51), lower scores of conscientiousness (52), extroversion (53) and openness to experience (53) have been demonstrated. A possible explanation for the relationship between higher levels of neuroticism and depression is that neuroticism is an important contributor for the development of psychological disorders and therefore these patients maybe more prone to depression $(6,54)$.

Exposure to stressful events in everyday life may increase depression, particularly in individuals with high levels of neuroticism, low levels of conscientiousness and openness to experience $(55,56)$. In addition, neuroticism may be associated with polymorphisms in the 5-HTT promoter region. The analysis of 133 healthy elite athletes by Petito et al (57) demonstrated that the 5-HTTLPR s/s genotype was associated with an increased neuroticism score. However, another study by Plieger et al (58) on 1,075 women found no evidence of an association between 5-HTT polymorphisms and neuroticism. 
Table III. Association of personality traits with depression in Baboli women aged 45-65 years old.

\begin{tabular}{|c|c|c|c|c|c|}
\hline NEO-FFI & Total, $\mathrm{n}=132$ & $\begin{array}{c}\text { No depressive } \\
\text { symptoms, } n=61\end{array}$ & $\begin{array}{c}\text { Depressive } \\
\text { symptoms, } n=71\end{array}$ & $\chi^{2}$ & P-value \\
\hline Neuroticism, n (\%) & & & & 20.067 & $<0.0001^{\mathrm{b}}$ \\
\hline Low & $32(24.2)$ & $25(78.1)$ & 7 (21.9) & & \\
\hline Average & $61(46.2)$ & $26(42.6)$ & $35(57.4)$ & & \\
\hline High & $39(29.5)$ & $10(25.6)$ & $29(74.4)$ & & \\
\hline Extroversion, n (\%) & & & & 23.756 & $<0.0001^{\mathrm{b}}$ \\
\hline Low & $29(22.0)$ & $3(10.3)$ & $26(89.7)$ & & \\
\hline Average & $30(22.7)$ & $12(40.0)$ & $18(60.0)$ & & \\
\hline High & $73(55.3)$ & $46(63.0)$ & $27(37.0)$ & & \\
\hline Openness, n (\%) & & & & 1.643 & 0.440 \\
\hline Low & $100(75.8)$ & $45(45.0)$ & $55(55.0)$ & & \\
\hline Average & $23(17.4)$ & $10(43.5)$ & $13(56.5)$ & & \\
\hline High & $9(6.8)$ & $6(66.7)$ & $3(33.3)$ & & \\
\hline Agreeableness, n (\%) & & & & 0.024 & $0.024^{\mathrm{a}}$ \\
\hline Low & $33(25.0)$ & $9(27.3)$ & $24(72.7)$ & & \\
\hline Average & $41(31.1)$ & $19(46.3)$ & $22(53.7)$ & & \\
\hline High & $58(43.9)$ & $33(56.9)$ & $25(43.1)$ & & \\
\hline Conscientiousness, n (\%) & & & & 21.422 & $<0.0001^{\mathrm{b}}$ \\
\hline Low & $10(7.6)$ & $1(10.0)$ & $9(90.0)$ & & \\
\hline Average & $39(29.5)$ & $9(23.1)$ & $30(76.9)$ & & \\
\hline High & $83(62.9)$ & $51(61.4)$ & $32(38.6)$ & & \\
\hline
\end{tabular}

${ }^{\mathrm{a}} \mathrm{P}<0.05,{ }^{\mathrm{b}} \mathrm{P}<0.001$. NEO-FFI, Neuroticism-Extroversion-Openness-Five Factor Inventory.

Table IV. Association between 5-HTTLPR genotype and MAO-A promoter region with menopausal symptoms in 132 Baboli women aged 45-65 years old.

\begin{tabular}{|c|c|c|c|c|c|c|c|}
\hline \multirow[b]{2}{*}{ Menopausal symptom severity } & \multirow[b]{2}{*}{$\mathrm{n}(\%)$} & \multicolumn{3}{|c|}{ 5-HTTLPR, n (\%) } & \multicolumn{3}{|c|}{ MAO A, n (\%) } \\
\hline & & $\mathrm{S} / \mathrm{S}$ & $\mathrm{L} / \mathrm{L}$ & $\mathrm{L} / \mathrm{S}$ & $3 / 3$ & $3 / 4$ & $4 / 4$ \\
\hline Minor & $54(40.9)$ & $7(46.7)$ & $32(40.0)$ & $15(40.5)$ & $10(45.5)$ & $18(37.5)$ & $26(41.9)$ \\
\hline Severe & $78(59.1)$ & $8(53.3)$ & $48(60.0)$ & $22(59.5)$ & $12(54.5)$ & $30(62.5)$ & $36(58.1)$ \\
\hline$\chi^{2}$ & - & 0.235 & & & 0.446 & & \\
\hline P-value & - & 0.889 & & & 0.800 & & \\
\hline
\end{tabular}

5-HTTLPR, 5-hydroxytryptamine transporter; MAO A, monoamine oxidase A; L, long; S, short.

Table V.Association between the 5-HTTLPR genotype and MAO-A promoter region with the severity of menopausal depression in 132 Baboli women aged 45-65 years old.

\begin{tabular}{|c|c|c|c|c|c|c|c|}
\hline \multirow{2}{*}{$\begin{array}{l}\text { Presence/absence } \\
\text { of depressive symptoms }\end{array}$} & \multirow[b]{2}{*}{$\mathrm{n}(\%)$} & \multicolumn{3}{|c|}{ 5-HTTLPR genotype, n (\%) } & \multicolumn{3}{|c|}{ MAO A, n (\%) } \\
\hline & & $\mathrm{S} / \mathrm{S}$ & $\mathrm{L} / \mathrm{L}$ & $\mathrm{L} / \mathrm{S}$ & $3 / 3$ & $3 / 4$ & $4 / 4$ \\
\hline No depressive symptoms & $61(67.2)$ & $8(11.3)$ & $42(59.2)$ & $21(29.6)$ & $8(13.1)$ & $24(39.3)$ & $29(47.5)$ \\
\hline Depressive symptoms & $71(53.8)$ & $8(11.3)$ & $42(59.2)$ & $21(29.6)$ & $14(19.7)$ & $24(33.8)$ & $33(46.5)$ \\
\hline$\chi^{2}$ & - & 0.186 & & & 1.143 & & \\
\hline P-value & - & 0.911 & & & 0.562 & & \\
\hline
\end{tabular}

5-HTTLPR, 5-hydroxytryptamine transporter; MAO A, monoamine oxidase A; L, long; S, short. 
There is a consensus among various researchers that 5-HTT polymorphisms may increase depression in individuals with a stressful life (26,59-61). However, other studies have shown that 5-HTT was not associated with depression (21) and the level of anxiety (62) in menopausal women. Additionally, the MAO-A promoter region was also previously shown to be not associated with depression or menopausal symptoms in menopausal women (21).

The results of these studies are directly in line with our previous findings (63). In the present study, there was no association between 5-HTT polymorphisms, and menopausal symptoms and depression, nor was there an association between polymorphisms of the MAO-A promoter region and menopausal symptoms and depression in menopausal women. In contrast to the results of the present study, Jurczak et al (20) showed there was a significant correlation between MAO-A polymorphisms of the promoter region and menopausal symptoms and depression in the post-menopausal women. Additionally in a study with 630 women with menopausal symptoms, 5HTTLPR gene polymorphisms were significantly more common in women with severe menopausal symptoms (21).

The present study had several limitations. First, it used a self-reporting questionnaire to determine the depressive and menopausal symptoms and personality traits, thus the results are not entirely objective. Demographic variables such as educational level and marital status that may be indirectly associated with menopausal symptoms or onset of depression were not assessed. History of amenorrhea for at least 12 months was determined through gynecological interview and was not confirmed by measuring FSH levels, and the small sample size and access to respondents may be another limitation of this study. Therefore, a larger sample size is required to confirm the associations between depressive and menopausal symptoms with personality traits, MAO-A and 5-HTT polymorphisms in menopausal women.

Despite these limitations, the strengths of the present study are: Community-based design, wide inclusion and exclusion criteria, an age group covering the mid-life age (45-65 years), the use of a cluster method for sampling, and the use of valid scale for assessing the menopausal symptoms. The primary strengths of the present study are that only healthy women were included in the study, and women with any other type of chronic disorders were excluded.

In conclusion, a significant relationship between personality traits and the severity of depressive and menopausal symptoms in menopause women was identified. Therefore, it is vital to counsel menopausal women to reduce the severity of depressive and menopausal symptoms, to improve their quality of life. Additionally, health care providers can reduce the severity of depressive and menopausal symptoms based on the personality of women, to identify those at increased risk.

\section{Acknowledgements}

Not applicable.

\section{Funding}

This study was financially supported by Babol University of Medical Sciences, Iran (grant no. 3460).

\section{Availability of data and materials}

The datasets used and/or analyzed during the current study are available from the corresponding author on reasonable request.

\section{Authors' contributions}

MAD and SMA contributed to interpreting data, and writing the manuscript. MAD contributed to the statistics analyses as well provided study material. SE, NA and RN contributed to data collection and writing the manuscript. HN and NA performed the genetic examination. All authors have read and approved the final version of the manuscript.

\section{Ethics approval and consent to participate}

Written informed consent was obtained from all subjects before the study. Ethics approval for this study was obtained from Babol University of Medical Science (approval no. MUBABOL,HRI.REC.1395.7).

\section{Patient consent for publication}

Not applicable.

\section{Competing interests}

The authors declare that they have no competing interests.

\section{References}

1. Hickey M, Bryant C and Judd F: Evaluation and management of depressive and anxiety symptoms in midlife. Climacteric 15: 3-9, 2012 .

2. Catalano A, Martino G, Bellone F, Gaudio A, Lasco C, Langher V, Lasco A and Morabito N: Anxiety levels predict fracture risk in postmenopausal women assessed for osteoporosis. Menopause 25: 1110-1115, 2018.

3. Kaunitz AM and Manson JE: Management of menopausal symptoms. Obstet Gynecol 126: 859-876, 2015.

4. Dalal PK and Agarwal M: Postmenopausal syndrome. Indian J Psychiatry 57(Suppl 2): S222-S232, 2015.

5. Labouvie-Vief G, Diehl M, Tarnowski A and Shen J: Age differences in adult personality: Findings from the United States and China. Gerontol B Psychol Sci Soc Sci 55(1): 4-17, 2000.

6. Lin MF, Ko HC, Wu JY and Chang FM: The impact of extroversion or menopause status on depressive symptoms among climacteric women in Taiwan: Neuroticism as moderator or mediator? Menopause 15: 138-143, 2008.

7. Elavsky S and McAuley E: Personality, menopausal symptoms, and physical activity outcomes in middle-aged women. Pers Individ Dif 46: 123-128, 2009.

8. Jahromi M, Moeen L and Yazdani L: Relationship between personality traits and marital satisfaction in women Kazeroun city. SID 1: 143-162, 2011.

9. Martino G, Catalano A, Bellone F, Langher V, Lasco C, Penna A, Nicocia G and Morabito N: Quality of life in postmenopausal women: Which role for vitamin D? Mediterranean J Clin Psychol (MJCP) 6: 14, 2018.

10. Martino G, Catalano A, Bellone F, Sardella A, Lasco C, Caprì T, Langher V, Caputo A, Fabio RA and Morabito N: Vitamin D status is associated with anxiety levels in postmenopausal women evaluated for osteoporosis. Mediterranean J Clin Psychol (MJCP) 6: 2018.

11. McCrae RR and Costa PT: The five-factor model of personality: Theoretical perspectives. Wiggins JS (ed). Guilford Press, New York, NY, pp51-87, 1996.

12. Costa PT Jr, Fagan PJ, Piedmont RL, Ponticas Y and Wise TN: The five-factor model of personality and sexual functioning in outpatient men and women. Psychiatr Med 10: 199-215, 1992. 
13. Jang KL, Livesley WJ and Vernon PA: Heritability of the big five personality dimensions and their facets: A twin study. J Pers 64: 577-591, 1996.

14. Power RA and Pluess M: Heritability estimates of the Big Five personality traits based on common genetic variants. Transl Psychiatry 5: e604, 2015.

15. Leonardo ED and Hen R: Genetics of affective and anxiety disorders. Annu Rev Psychol 57: 117-137, 2006.

16. Lieben CK, Blokland A, Westerink B and Deutz NE: Acute tryptophan and serotonin depletion using an optimized tryptophan-free protein-carbohydrate mixture in the adult rat. Neurochem Int 44: 9-16, 2004.

17. Maes M, Leonard BE, Myint AM, Kubera M and Verkerk R: The new ' 5 -HT' hypothesis of depression: Cell-mediated immune activation induces indoleamine 2,3-dioxygenase, which leads to lower plasma tryptophan and an increased synthesis of detrimental tryptophan catabolites (TRYCATs), both of which contribute to the onset of depression. Prog Neuropsychopharmacol Biol Psychiatry 35: 702-721, 2011.

18. Maes M, Ringel K, Kubera M, Berk M and Rybakowski J: Increased autoimmune activity against 5-HT: A key component of depression that is associated with inflammation and activation of cell-mediated immunity, and with severity and staging of depression. J Affect Disord 136: 386-392, 2012.

19. Słopień R, Słopień A, Różycka A, Warenik-Szymankiewicz A Lianeri M and Jagodziński P: The c. 1460C $>$ T polymorphism of $\mathrm{MAO}-\mathrm{A}$ is associated with the risk of depression in postmenopausal women. ScientificWorldJournal 2012: 194845, 2012

20. Jurczak A, Szkup M, Wieder-Huszla S, Grzywacz A Samochowiec A, Karakiewicz B, Samochowiec J and Grochans E: The assessment of the relationship between personality, the presence of the 5HTT and MAO-A polymorphisms, and the severity of climacteric and depressive symptoms in postmenopausal women. Arch Womens Ment Health 18: 613-621, 2015.

21. Grochans E, Grzywacz A, Jurczak A, Samochowiec A, Karakiewicz B, Brodowska A, Starczewski A and Samochowiec J: The 5HTT and MAO-A polymorphisms associate with depressive mood and climacteric symptoms in postmenopausal women Prog Neuropsychopharmacol Biol Psychiatry 45: 125-130, 2013.

22. Broekmans FJ, Soules MR and Fauser BC: Ovarian aging: Mechanisms and clinical consequences. Endocr Rev 30: 465-493, 2009.

23. Henderson VW and Sherwin BB: Surgical versus natural menopause: Cognitive issues. Menopause 14: 572-579, 2007.

24. Thurston RC, Matthews KA, Hernandez J and De La Torre F: Improving the performance of physiologic hot flash measures with support vector machines. Psychophysiology 46: 285-292, 2009.

25. Schneider-Matyka D, Jurczak A, Samochowiec A, Karakiewicz B, Szkup M, Grzywacz A and Grochans E: Analysis of personality traits and their influence on the quality of life of postmenopausal women with regard to genetic factors. Ann Gen Psychiatry 15: $25,2016$.

26. Grochans E, Szkup M, Kotwas A, Kopec J, Karakiewicz B and Jurczak A: Analysis of sociodemographic, psychological, and genetic factors contributing to depressive symptoms in pre-, periand postmenopausal women. Int J Environ Res Public Health 15: E712, 2018.

27. Nathanson V: Revising the declaration of helsinki. BMJ 346: f2837, 2013.

28. Garcia-Diz L, Goñi I and Varela G: Use of the calculation of anthropometric values with microprocessors for nutritional diagnosis. Arch Latinoam Nutr 35: 48-62, 1985 (In Spanish).

29. Higgins D: Patient assessment part 5-measuring pulse. Nurs Times 104: 24-25, 2008.

30. Sherman S: Defining the menopausal transition. Am J Med 12B (Suppl 188): 3-7, 2005.

31. Australasian Menopause Society: Diagnosing Menopause, AMS Diagnosing Menopause Symptom score sheet. http:// www.menopause.org.au/hp/information-sheets/420-diagnosing-menopause.

32. Greene JG: Constructing a standard climacteric scale. Maturitas 29 : 25-31, 1998.

33. Greene JG: Constructing a standard climacteric scale. Maturitas 61: 78-84, 2008

34. Derman RJ, Dawood MY and Stone S: Quality of life during sequential hormone replacement therapy-a placebo-controlled study. Int J Fertil Menopausal Stud 40: 73-78, 1995.

35. Alder EM, Bancroft J and Livingstone J: Estradiol implants, hormone levels and reported symptoms. J Psychosomatic Obstetrics Gynecol 13: 223-235, 1992.
36. Delavar MA and Hajiahmadi M: Age at menopause and measuring symptoms at midlife in a community in Babol, Iran. Menopause 18: 1213-1218, 2011.

37. Beck AT and Beck RW: Screening depressed patients in family practice. A rapid technic. Postgrad Med 52: 81-85, 1972.

38. Edelstein BA, Drozdick LW and Ciliberti CM: Assessment of depression and bereavement in older adults. In: Handbook of Assessment in Clinical Gerontology. Elsevier Academic Press, Cambridge, MA, pp3-43, 2010.

39. Rajabi GR: Psychometric properties of Beck depression inventory short form items (BDI-13). J Iran Psychologists 1: 291-298, 2005.

40. Costa PT Jr and McCrae RR: Revised NEO personality inventory (NEO-PI-R) and NEO five-factor (NEO-FFI) inventory professional manual. Boyle GJ, Matthews G and Saklofske DH (eds). PAR, Odessa, FL, 1992.

41. Garousi Farshi MT, Mehryar AH and Ghazi Tabatabaie MG: Application of the NEO PIR test and analytic evaluation of its characteristics and factorial structure among Iranian university students. Sci Information Database 11: 173-198, 2001.

42. Miller SA, Dykes DD and Polesky HF: A simple salting out procedure for extracting DNA from human nucleated cells. Nucleic Acids Res 16: 1215, 1988.

43. Edgnulu TG, Ozge A, Erdal N, Kuru O and Erdal ME: Association analysis of the functional MAOA gene promoter and MAOB gene intron 13 polymorphisms in tension type headache patients. Adv Clin Exp Med 23: 901-906, 2014.

44. Zhang X, Wang L, Huang F, Li J, Xiong L, Xue H and Zhang Y: Evaluation of the promoter region polymorphism (5-HTTLPR) in the serotonin transporter gene in females with postpartum depression. Exp Ther Med 9: 245-249, 2015.

45. Nilsson KW, Comasco E, Aslund C, Nordquist N, Leppert J and Oreland L: MAOA genotype, family relations and sexual abuse in relation to adolescent alcohol consumption. Addict Biol 16 : 347-355, 2011.

46. Oreland L, Nilsson K, Damberg M and Hallman J: Monoamine oxidases: Activities, genotypes and the shaping of behaviour. J Neural Transm (Vienna) 114: 817-822, 2007.

47. Zimmermann-Peruzatto JM, Almeida S, Lucion AB, Oses JP, Quevedo LA, Pinheiro KA, da Silva RA and Pinheiro RT: Evaluation of the 5-HTTLPR and 5-HTTVNTR polymorphisms in the serotonin transporter gene in women with postpartum depression. Neurosci Med 3: 275-280, 2012.

48. GhorbaniM,AzhariS,EsmailyHAandGhanbariHashemabadiBA: Investigation of the relationship between personality characteristics and vasomotor symptoms in menopausal women. Iran J Nurs Midwifery Res 21: 441-447, 2016.

49. Bromberger JT and Epperson CN: Depression during and after the perimenopause: Impact of hormones, genetics, and environmental determinants of disease. Obstet Gynecol Clin North Am 45: 663-678, 2018.

50. Hakulinen C, Elovainio M, Pulkki-Raback L, Virtanen M, Kivimaki $\mathrm{M}$ and Jokela M: Personality and depressive symptoms: Individual-participant meta-analysis of 10 cohort studies. Depress Anxiety 32: 461-470, 2015.

51. Vink D, Aartsen MJ, Comijs HC, Heymans MW, Penninx BW, Stek ML, Deeg DJ and Beekman AT: Onset of anxiety and depression in the aging population: Comparison of risk factors in a 9-year prospective study. Am J Geriatr Psychiatry 17: 642-652, 2009.

52. Hayward RD, Taylor WD, Smoski MJ, Steffens DC and Payne ME: Association of five-factor model personality domains and facets with presence, onset, and treatment outcomes of major depression in older adults. Am J Geriatr Psychiatry 21: 88-96, 2013.

53. Weber K, Giannakopoulos P, Delaloye C, de Bilbao F, Moy G, Moussa A, Rubio MM, Ebbing K, Meuli R, Lazeyras F, et al: Volumetric MRI changes, cognition and personality traits in old age depression. J Affect Disord 124: 275-282, 2010.

54. Bosworth HB, Bastian LA, Rimer BK and Siegler IC: Coping styles and personality domains related to menopausal stress. Womens Health Issues 13: 32-38, 2003.

55. van der Veen DC, van Dijk SD, Comijs HC, van Zelst WH, Schoevers RA and Oude Voshaar RC: The importance of personality and life-events in anxious depression: From trait to state anxiety. Aging Ment Health 21: 1177-1183, 2017.

56. Cohen LS, Soares CN, Vitonis AF, Otto MW and Harlow BL: Risk for new onset of depression during the menopausal transition: The Harvard study of moods and cycles. Arch Gen Psychiatry 63: 385-390, 2006. 
57. Petito A, Altamura M, Iuso S, Padalino FA, Sessa F, D'Andrea G, Margaglione $M$ and Bellomo A: The relationship between personality traits, the 5HTT polymorphisms, and the occurrence of anxiety and depressive symptoms in elite athletes. PLoS One 11: e0156601, 2016.

58. Plieger T, Montag C, Felten A and Reuter M: The serotonin transporter polymorphism (5-HTTLPR) and personality: Response style as a new endophenotype for anxiety. Int J Neuropsychopharmacol 17: 851-858, 2014.

59. Paaver M, Kurrikoff T, Nordquist N, Oreland L and Harro J: The effect of 5-HTT gene promoter polymorphism on impulsivity depends on family relations in girls. Prog Neuropsychopharmacol Biol Psychiatry 32: 1263-1268, 2008.

60. Serretti A, Calati R, Mandelli L and De Ronchi D: Serotonin transporter gene variants and behavior: A comprehensive review. Curr Drug Targets 7: 1659-1669, 2006.
61. Wilhelm K, Mitchell PB, Niven H, Finch A, Wedgwood L, Scimone A, Blair IP, Parker G and Schofield PR: Life events, first depression onset and the serotonin transporter gene. Br J Psychiatry 188: 210-215, 2006.

62. Grochans E, Jurczak A, Szkup M, Samochowiec A, WloszczakSzubzda A, Karakiewicz B, Grzywacz A, Brodowska A and Samochowiec J: Evaluation of the relationship between 5-HTT and MAO gene polymorphisms, mood and level of anxiety among postmenopausal women. Int J Environ Res Public Health 12: 268-281, 2014.

63. Middeldorp CM, de Geus EJ, Willemsen G, Hottenga JJ, Slagboom PE and Boomsma DI: The serotonin transporter gene length polymorphism (5-HTTLPR) and life events: No evidence for an interaction effect on neuroticism and anxious depressive symptoms. Twin Res Hum Genet 13: 544-549, 2010. 